\title{
Rescuing doctors in distress
}

$\mathrm{T}$

here is no shortage of causes of burnout or depression among physicians: financial cuts, relentless night shifts, long hours of work, overwhelming responsibility, dealing with life-threatening conditions, distress over the limitations of medical care, or just working conditions that have worsened in recent decades as a result of increasing time pressure, competition, explosion of knowledge, administrative loads or lack of autonomy. And that doesn't begin to address the explosive growth of patients' demands.

The consequences often include medical errors brought on by a lack of concentration and motivation. They can include physical symptoms such as palpitations, sleep disorders or stomach upsets, as well as social effects such as withdrawal or problems with personal relationships. It can also lead to clinical depression, substance abuse and psychosomatic disorders.

Yet, many doctors don't know where to turn for help, although many countries and individual health facilities do have crisis lines, Balint-groups and contact points. Often, doctors may become aware of their distress too late or are reluctant to admit a problem, particularly to people working in the same environment.

"For a medical doctor it is difficult to accept that one has a serious problem, is in need of help and may become a patient oneself," says Dr. Michael Peltenburg, a general practitioner in Hinwil, Switzerland.

Switzerland hopes it has found a solution to that problem in the form a program called ReMed (Rete Medicorum), a support network that helps doctors in crisis or under extreme pressure to get help from their medical colleagues.

Founded by physicians in 2007 , ReMed "rescues" colleagues with professional and personal problems by means of crisis intervention, mentoring and coaching. In special cases, such as when a doctor's licence to practice medicine is at risk, it even offers counselling as part of a treatment plan.

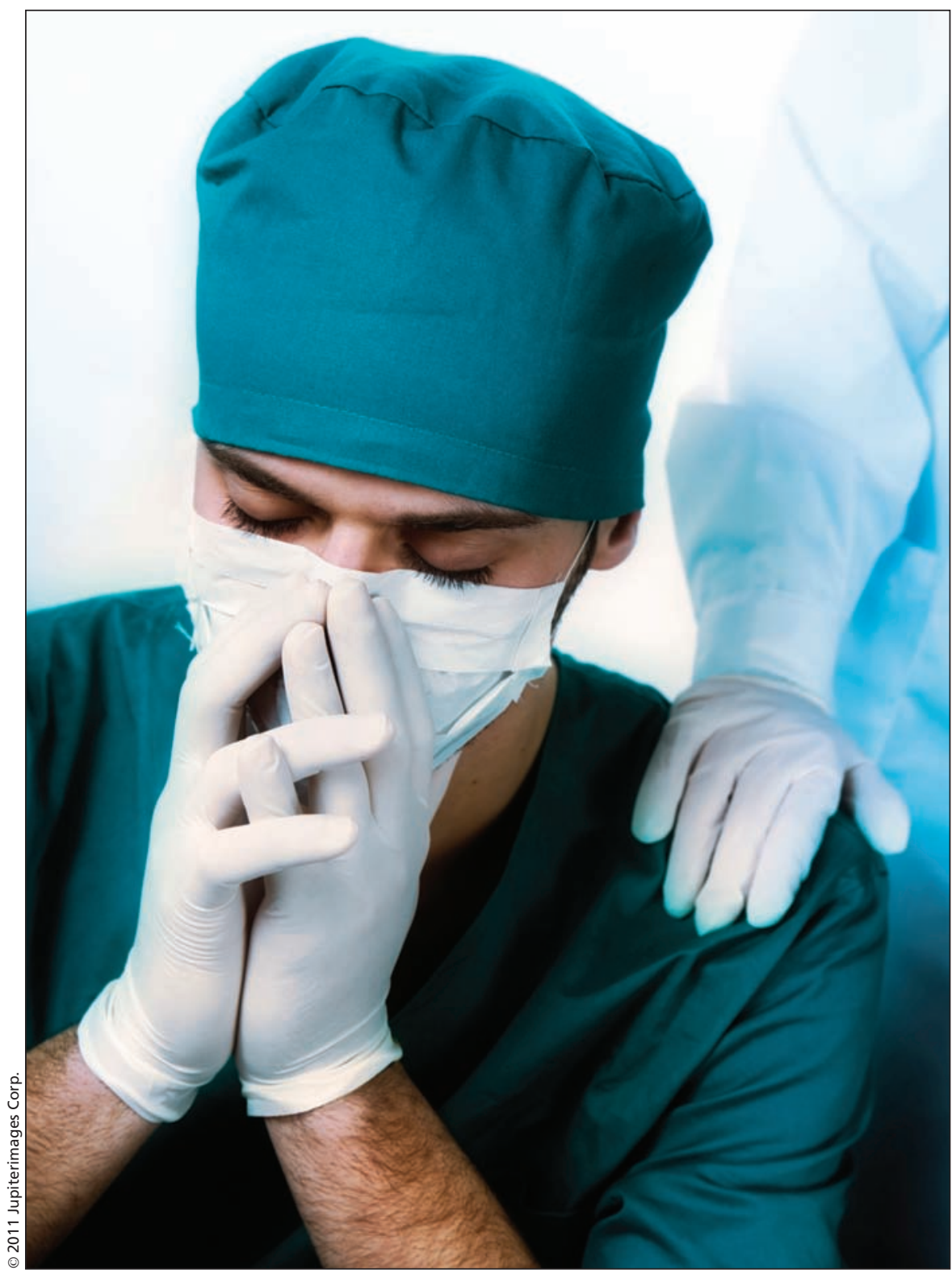

Doctors are often reluctant to admit a problem, particularly to people working in the same environment.

After a three-year pilot phase in the Swiss cantons of Thurgau and Neuenburg, ReMed is being rolled out nationally to help doctors deal with burnout, emotional exhaustion, depersonalization and other forms of distress.

Sponsored and financed by the Federation Medical Helvetica and the Swiss Medical Association, the program offered assistance to more than
80 doctors during the three-year pilot. Over 100 people visited the ReMed website monthly.

According to program administrators, the foremost reason that doctors contacted ReMed was burn-out and depression $(43 \%)$, followed by practice and everyday life problems $(32 \%)$, addiction (13\%), feelings of guilt following a professional error, inability to 
work following an accident, post-traumatic stress and legal proceedings $(12 \%)$. Two people had suicidal thoughts. Women $(56 \%)$ were affected slightly more than men. The mean age was 50 years with a quarter under the age of 45. Among these were a lot of young doctors at the start of their careers numbed by their daily work-life and its hierarchic structures. One-third of the callers were already undergoing some form of treatment at the time of contact.

Distressed doctors can confidentially contact ReMed via a telephone hotline, by email or online. Staff refer inquiries to a medical executive committee comprised of four physicians, one of whom contacts the doctor within 72 hours to work out a remedial action plan. Most problems are resolved through acute crisis intervention, coaching or mentoring.
In other cases ReMed may effect a special intervention - the so-called assessment.

If, for example, a doctor is alcoholic and under threat of losing his licence to practise because of medical miscues, an assessment will be developed in conjunction with external psychiatric or legal experts. The end result is often a written contract between the doctor and ReMed defining the intervention and how progress will be measured. Typically, a report outlining the plan is delivered to a doctor's employer.

In cases where doctors need treatment, the physician chooses the sex and specialty of the therapist from a list maintained by the network. The nature and cost of the treatment is also discussed. Insurance companies can sometimes absorb some of the cost. In cases involving a full-scale "assess- ment," a doctor contributes $8 \%$ of his net income per year toward treatment.

"Mentoring, coaching and assessment are not intended to control or punish," says Peltenburg, a cofounder of ReMed. The goal is to restore the confidence of doctors so that they can continue to safely deliver medical care, while destigmatizing disorders resulting from physician stress.

ReMed is not the only program of its kind in Europe. The United Kingdom, Spain and Norway established similar programs and all participate in the European Association for Physician Health. But several countries, such as Germany, do not have national initiatives and ReMed may serve as a model for their development. - Claire Hegenbarth MD, Berlin, Germany

CMAJ 2011. DOI:10.1503/cmaj.109-3760 